\title{
A INTELIGÊNCIA ARTIFICIAL E O PANORAMA CONTEMPORÂNEO DA FILOSOFIA DA MENTE EM UM ESTUDO INTRODUTÓRIO PARA A FORMA ELETRÔNICA DO PROCESSO
}

\section{ARTIFICIAL INTELLIGENCE AND THE CONTEMPORARY PANORAMA OF THE PHILOSOPHY OF MIND IN A INTRODUCTORY STUDY FOR AN ELETRONIC FORM OF PROCEDURE}

Resumo: Os avanços tecnológicos, como é de conhecimento geral, demoram a ser plenamente incorporados pelo Poder Judiciário, em função da resistência sistemática e anacrônica, que pode ser constatada, com raras exceções, nos órgão que o integram em todo o País. Esses aparatos causam natural estranheza inicial, mas, na verdade, não provocam qualquer prejuízo; ao contrário, colaboram para a celeridade e efetividade da prestação da tutela jurisdicional. É por isso que, atualmente, os Tribunais não anulam mais decisões e atos processuais elaborados sob a forma datilografada, através do uso de microcomputadores ou mesmo pela utilização de impressoras a laser. Nesse contexto, o propósito deste trabalho é demonstrar a possibilidade de utilização de recursos tecnológicos disponíveis em processos judiciais, como forma de promover o aprimoramento e a efetividade das atividades jurisdicionais. Os recursos cibernéticos em desenvolvimento, como serão expostos, poderão complementar, inclusive, o exercício da jurisdição, através da utilização da Inteligência Artificial.

Palavras-chave: Filosofia da mente. Processo judicial. Inteligência artificial.

Abstract: Technological advances, as it is of general knowledge, take to be fully incorporated by the judiciary, in the light of systematic resistance and anachronistic, which can be found, with rare exceptions, in the organ that integrates it throughout the country. These apparatus cause natural initial strangeness, but in fact do not cause any injury; On the contrary, they collaborate for the speed and effectiveness of the provision of judicial protection. That is why, nowadays, the courts do not annul

\footnotetext{
${ }^{1}$ Doutor em Direito Civil pela Universidade do Estado do Rio de Janeiro - UERJ (2005), Doutor em Filosofia pela Universidade Federal do Rio de Janeiro - UFRJ (2007), Doutor em Ciências em História das Ciências, das Técnicas e Epistemologia pela Universidade Federal do Rio de Janeiro - UFRJ (2007), Doutor em Ciências Ambientais e Florestais pela Universidade Federal Rural do Rio de Janeiro - UFRRJ (2015), Mestre em Direito Civil pela Universidade do Estado do Rio de Janeiro UERJ (2002) e Mestre em Direito Constitucional pela Universidade Federal Fluminense - UFF (2013). Professor Adjunto da Universidade Federal do Estado do Rio de Janeiro - UNI-RIO. Professor no Programa de Pós-Graduação em Direito da Universidade Federal do Estado do Rio de Janeiro - UNIRIO. Desembargador do Tribunal Regional Federal da $2^{\mathrm{a}}$ Região (Rio de Janeiro e Espírito Santo).
} 
any more decisions and procedural acts elaborated in the typed form, through the use of microcomputers or even using laser printers. In this context, the purpose of this work is to demonstrate the possibility of using technological resources available in judicial proceedings, as a way to promote the improvement and effectiveness of judicial activities. The developing cyber-resources, as they will be exposed, can complement the exercise of jurisdiction through the use of Artificial intelligence.

Keywords: Philosophy of mind. Legal procedures. Artificial intelligence. 


\section{INTRODUÇÃO}

Em 1929, a Câmara Criminal do Tribunal da Relação de Minas Gerais anulou sentença, proferida por juiz de primeiro grau, sob o fundamento de que a decisão não havia sido escrita, de próprio punho, por seu subscritor. Na verdade, a sentença anulada havia sido datilografada. O Tribunal mineiro considerou que o uso da máquina de escrever seria incompatível com um dos princípios basilares do processo penal: o sigilo das decisões, antes de sua publicação.

Da mesma forma, na década de 20 do século passado, um juiz de direito do Estado do Rio de Janeiro anulou peças de inquérito, sob o argumento de que o delegado as datilografou, ao invés de elaborá-las de forma manuscrita. Nesse último caso, o Tribunal de Justiça desse Estado reformou a decisão do juiz.

Mais recentemente, nos anos oitenta, várias sentenças foram anuladas pelos Tribunais, porque os juízes haviam utilizado na sua elaboração o então desconhecido microcomputador. Os Tribunais justificaram a anulação das decisões no fato de que o novo equipamento permitia a reprodução de sentenças, em série, e, com isso, restaria prejudicada a atuação, do magistrado para as peculiaridades de cada caso.

O uso de impressora a laser, na década de noventa, gerou dificuldades práticas, pois muitos funcionários do Poder Judiciário só conheciam a reprodução material dos textos e documentos levados aos Tribunais pelos advogados.

Os Tribunais, atualmente, têm invalidado interrogatórios realizados, no curso de processos criminais, por meio de videoconferência. Segundo as decisões nesse sentido, os princípios constitucionais que garantem o devido processo legal e o direito à ampla defesa seriam desrespeitados com o uso desse instrumento de reprodução do ato de interrogar.

Os Tribunais exigem até hoje, para a validade do ato, que o interrogatório seja procedido com a presença física do réu e do juiz. Dessa exigência decorrem inúmeros inconvenientes, tais como a necessidade de escolta do réu do presídio até a sala de audiência e seu posterior retorno, com todos os riscos para os policiais e para toda a população, decorrentes desses deslocamentos. Um forte aparato policial é criado para acompanhar o descolamento do preso. Muitas vezes, são necessários 
aviões, helicópteros e barcos para a realização dessas empreitadas. O risco de fuga ou pior, de resgate, durante esses deslocamentos - que podem redundar em tiroteios e ferimento de inocentes - é acentuado, se comparado à estrutura de segurança que se pode obter no interior dos presídios. Além disso, em cada deslocamento são despendidos expressivos recursos públicos. Não se deve ignorar o efeito secundário do uso urbano de escoltas, como o tumulto no trânsito e o de submeter pessoas inocentes à mira de armas de alto calibre.

A esses fatos deve-se acrescentar 0 de que os procedimentos realizados dentro do Fórum, que exigem o isolamento de cada preso até que seja levado perante o juiz, demandam intensas ações policiais, armadas e organizadas. Nesse contexto, um número expressivo de policiais que poderiam estar nas ruas, a serviço da segurança pública, está escoltando réus presos, em todos Estados da Federação.

Esse tema tem sido amplamente debatido em todo o País. Recentemente, o rumoroso processo criminal que redundou na prisão do conhecido "Fernandinho Beira-Mar" levou a Presidência da República a decidir pela construção do primeiro presídio federal de segurança máxima. Mas o Poder Executivo não convenceu os Tribunais Superiores a permitir a realização de interrogatórios no presídio, por meio de videoconferências. Insistem os Tribunais que esse ato deverá ser praticado com a presença do réu perante o juiz. No caso específico, as dificuldades e os riscos envolvidos nesse procedimento são inegáveis.

Todos esses avanços tecnológicos encontraram obstáculos que, ao longo do tempo, foram superados ou aperfeiçoados. O caráter inovador da nova tecnologia encontrou dificuldades na sua adaptação, mas, por outro lado, argumentos fundados foram adotados na solução de cada um desses problemas. Um dos temas mais atuais é a criação de modelos para a Inteligência Artificial e a construção de sistemas computacionais com essas habilidades. A ausência de qualquer exploração ou experimentação de técnicas computacionais, que apresentem potencial para a simulação do comportamento inteligente, é uma boa prova disso. Em várias ocasiões, o debate limitou-se ao acesso à informação e à redução de custos e arquivos necessários ao exercício das atividades do juiz. Em nenhum 
momento a ideia de modelos formais de inteligência humana, com aplicação estrita em julgamentos, alçou o patamar de debate acadêmico ou formal.

\section{DESENVOLVIMENTO}

Sem se perder naquilo que os escolásticos denominavam de circuitus inutilis, bem caracterizados talvez na superficialidade dos formalismos exagerados ou mesmo nas aplicações mais trabalhosas e complexas da Inteligência Artificial, especialmente quantos aos seus fundamentos matemáticos e lógicos, a organização de qualquer ideia sobre o assunto exige a superação de problemas fundamentais relacionados à atividade do juiz em vista do debate das Ciências Cognitivas, especialmente quanto às Teorias da Mente.

Deve ser lembrado que a Lei $n^{0} 11.419$, de 19 de dezembro de 2006, já dispôs sobre a informatização dos processos nos tribunais brasileiros. A referida norma contempla, inclusive, a criação de processos eletrônicos. Mas poderá ela resolver as questões relativas aos princípios conceituais que, no passado, levaram à rejeição da utilização de avanços tecnológicos em auxilio à atividade jurisdicional?

De todos os problemas que a Filosofia da Mente vem enfrentando, nenhum encontra maior dificuldade de solução do que a controvérsia sobre a utilização da Inteligência Artificial em complementação ou no exercício da própria atividade de julgar. Prevalece, sobre o tema, a orientação de que a mente humana não poderia ser substituída no exercício da atividade de julgar. A celeuma instaurada sobre essa possibilidade tem como principal fundamento a seguinte premissa: o campo de desenvolvimento e evolução da Inteligência Artificial seria incompatível com a atividade de decidir, em razão de se considerar insubstituível a consciência do juiz e a sua capacidade de emitir a vontade do Estado?

O juiz fala pelo Estado como se fosse o próprio Estado. Ele não é um representante do Estado, mas um agente do órgão Estado, como conclui a Teoria do Órgão. De maneira que, em uma linguagem mais simples, o magistrado empresta a sua própria garganta para o Estado pronunciar a sua vontade. Os atos do juiz não são, pois, atos de inteligência, são atos de vontade. São atos volitivos do próprio Estado, pronunciados por ele juiz. Embora nenhuma vontade exista que não tenha 
sido produzida a partir de uma de inteligência, os atos do juiz correspondem, inegavelmente, a uma atividade de inteligência.

O automatismo que poderia ser propiciado por técnicas de Inteligência Artificial preencheria o conteúdo do ato. Porém, o ato de decidir não é reconhecido pelo seu conteúdo de inteligência, mas sim pela vontade declarada pelo juiz. Para o leigo, pode parecer que o ato do juiz seja um ato de expertise. Pode-se admitir que o ato do juiz contenha expertise, porém o seu ato é preponderantemente de vontade, mesmo que não seja reputado correto, inteligente ou mesmo justo.

Dessa forma, é relevante esclarecer quais as relações estabelecidas entre os atos de vontade e os atos de inteligência. Sem essa necessária distinção, não se poderá realizar a iniciativa profícua de lançar mão dos recursos de Inteligência Artificial em auxilio à atividade jurisdicional.

Para empreender essa demarcação, deve-se enveredar por diversas questões suscitadas pelas Teorias da Mente, de forma a estabelecer os mecanismos correlacionais entre inteligência e vontade. Esse é o primeiro obstáculo conceitual a ser enfrentado. O segundo obstáculo conceitual é a pessoalidade do ato do agente-juiz que, cercado das garantias de independência e imparcialidade, tornase, então, apto ao exercício da função jurisdicional.

\subsection{O Comportamentismo}

O Comportamentismo refuta qualquer forma de introspecção. O único dado de fato objetivo para um estudo científico da mente é o comportamento exterior. A mente é efetivamente tratada pelos adeptos dessa teoria como uma "caixa preta". São seus defensores John Watson e Burrhs Skinner (DI FRANCESCO, 2002, p. 107).

John Broadus Watson é considerado o pai do Comportamentismo, ou Comportamentalismo ou simplesmente Behaviorismo, a escola da psicologia de conduta, nascida da observação do comportamento dos animais. Watson era psicólogo, aluno do funcionalista James Angell e professor da Universidade John Hopkins, da qual foi despedido por suas relações pessoais com uma aluna. Após 
seu desligamento da universidade, ele foi imediatamente admitido Agência de Publicidade J. Walter Thompson Company.

Burrhus Frederic Skinner, conhecido psicólogo norte-americano, dedicou-se ao estudo da língua e literatura inglesas. Mais tarde, Burrhus Skinner obteve doutorado em Psicologia, pela Universidade de Harvard (DI FRANCESCO, 2002).

Filósofos próximos a essa corrente, não obstante não sejam essencialmente comportamentalistas, foram inspiradores do comportamentismo. Destacam-se, dentre eles, Gilbert Ryle e Wilfrid Sellars (DI FRANCESCO, 2002, p. 108).

Ryle questionou o cartesianismo e a doutrina segundo a qual existe uma fantasma na máquina (o corpo). Também foi Ryle quem impugnou a teoria segundo qual a mente é uma substância. Segundo ele, essa ideia apoia-se num erro de categoria, já que, segundo sua doutrina, a mente é um nome, mas, na realidade, não nomeia um objeto. Para Ryle, o cartesianismo confunde a lógica do discurso a respeito das mentes com a lógica do discurso a respeito dos corpos. A mente não seria o mesmo que possuir um tipo especial de identidade, o que significa simplesmente ter certas capacidades e disposições. Também sustentava Ryle que seria um erro considerar os estados mentais como crença, ou o desejo e a intenção como causas internas do comportamento, pois esses dados são meras disposições para se comportar de maneira aberta.

Embora Ryle possa ser classificado como behaviorista, no seguimento lógico do behaviorismo, na verdade ele não estava comprometido com a tese segundo a qual toda fala mental pode ser traduzida em fala comportamental (TEIXEIRA, 2005, p. 72).

A obra mais importante do filósofo Wilfrid Sellars é o longo e difícil artigo Empiricism and the Philosophy of Mind $^{2}$, no qual foi aprofundada a discussão, denominada de Myth of de the Given. As grandes linhas dessa obra designam umas das teses centrais da Fenomenologia e do Representacionalismo: a de que nós extraímos das experiências perceptivas os conhecimentos que são independentes, e, em um certo sentido, anteriores ao cômputo de outros conceitos que tornam

\footnotetext{
${ }^{2}$ Reproduced with the permission of the University of Minnesota Press from: Wilfrid Sellars, "Empiricism and the Philosophy of Mind," in Herbert Feigl and Michael Scriven, eds., Minnesota Studies in the Philosophy of Science, Volume I: The Foundations of Science and the Concepts of Psychology and Psychoanalysis (University of Minnesota Press, 1956), p. 253-329.
} 
possível nossa percepção dos objetos. Sellars persegue sua análise, por meio do estabelecimento de crítica ao Myth of Jones, concepção filosófica cujo fim é explicar como os pensamentos, as ações racionais e mesmo as experiências subjetivas internas podem ser atribuídas a certos comportamentos, sem nenhum recorte às concepções behavioristas mais estudadas. A contribuição de Sellars não se limitou às idéias, mas concebeu expressões como "espaço da razão". Ele desenvolveu a descrição de uma rede conceitual e comportamental, que permite aos seres humanos, frente aos processos da realidade.

\subsection{A Teoria da identidade}

Sustenta a Teoria da Identidade que só existe uma realidade substancial: a realidade física, a realidade material. A mente é considerada idêntica ao cérebro. Todos os fenômenos cerebrais se identificam com o particular estado ou processo mental. De maneira que a mente passa a ser qualquer coisa de material e os estados mentais seriam estados cerebrais. A premissa na qual está assentada a teoria tornaria possível a solução integrada dos problemas da mente e do cérebro (DI FRANCESCO, 2002, p. 115).

Os críticos dos teóricos da identidade insurgiram-se sobretudo contra o dualismo de Descartes, o qual, nos seus objetivos, não resolveu o problema mentecorpo, enquanto se limitava a explicar a mente com o conceito ad hoc de res cogitans, ou, em sentido lato, mente, consciência e figuras correlatas. De fato, isso não explicava como seria possível que uma substância imaterial e inextensa (res cogitans) poderia agir sobre qualquer coisa de extenso e material (res extensa), e como a sua volta uma substância corpórea poderia influenciar uma substância incorpórea (DI FRANCESCO, 2002).

Os teóricos da identidade, ao contrário, esperam superar esse pseudoproblema afirmando que os estados mentais não são outra coisa que estados cerebrais e, então, todas as propriedades da mente seriam, em realidade, possuídas pelo cérebro (DI FRANCESCO, 2002, p. 115).

Essas assertivas levam os teóricos da identidade à particular situação de negar a existência de introspecção subjetiva e das qualidades experimentadas 
fenomenologicamente pelo sujeito (os chamados qualia, ou qualidades da experiência pertencentes ao mundo essencialmente privado do sujeito, como as cores e os sabores). Em tal sentido, os estados mentais não seriam outra coisa que disposições a fazer ações peculiares, determinadas pelos estados cerebrais. Isso significava que o estado mental de um indivídulo reduz-se ao ato cerebral e ao comportamento que esse estado determina.

A Teoria da Identidade acolhe também o desafio dos qualia e busca dar uma solução compatível com a própria Epistemologia. Assim, o estado mental da dor é um estado cerebral que pode consistir, por exemplo, na elaboração de fibras nervosas (as fibras C). De acordo com esse ponto de vista, advertir da dor é ter as fibras- $C$, que permitem ver o vermelho e ter certas células do cortex cerebral, em um estado específico (Teoria da identidade tipo-tipo). São adeptos dessa forma de pensar Ullin Place, John Jamieson Smart e David Armstrong (DI FRANCESCO, 2002).

\subsection{O Funcionalismo}

O Funcionalismo é a Teoria da Mente desenvolvida por Hilary Puttnam nos anos cinquenta, em contraposição ao reducionismo materialista, a fim de superar o debate dual entre mente e cérebro na Filosofia. A ideia base do Funcionalismo é a de que os estados mentais como o desejo e o prazer seriam a sua função, a sua reação causal, a respeito de outros estados mentais, percepções e comportamentos. Se os estados mentais poderiam ser definidos em bases definitivas ao seu papel funcional, eles seriam multiplicadamente realizáveis, ou seja, poderiam manifestarse em vários sistemas, também artificiais, como, por exemplo, na função calculadora se o sistema computa outras funções.

As origens do Funcionalismo remontam ao Século XIX, com o filósofo inglês George Henry Lewes, que afirmou que enquanto todo evento neurológico é mental, todo evento mental é neurológico. Ele declarou que o que faz com que certos eventos neurológicos sejam eventos mentais é a sua função causal dentro do organismo (DI FRANCESCO, 2002). 
São adeptos do Funcionalismo Hilary Putnam e Jerry Fodor. Jerry Allan Fodor é um filósofo da linguagem e é o mais proeminente estudioso do Funcionalismo. Seus escritos sobre Filosofia da mente e da ciência cognitiva são deveras conhecidos, e lastreiam-se na tese da modularidade da mente e da linguagem do pensamento. Segundo essa orientação, o módulo da linguagem seria inato e, em consequência, a aprendizagem não seria outro fenômeno senão uma confirmação das hipóteses. São também de Fodor argumentos de Epistemologia contra o Reducionismo. Após os anos sessenta, defendeu Fodor um programa funcionalista na Filosofia das ciências cognitivas. Segundo essa concepção, os estados mentais são reais e eles são definidos por seu papel funcional. Tais assertivas contrariaram as conhecidas teses behaviorista e eliminativista. Para ele, a estrutura da cada linguagem do pensamento será inata, tal como uma sintaxe de gramática universal. O espírito terá uma arquitetura com os módulos especiais e o módulo sensorial será isolado dos conceitos (DI FRANCESCO, 2002, p. 124).

As pesquisas de Daneil Dennett ocupam-se da consciência, da Filosofia da Mente e da Inteligência Artificial. Ele é reconhecido por ter elaborado o conceito de sistema intencional. Também contribuiu para a fundamentação conceitual da Biologia Evolucionista. Nos seus estudos das Ciências Cognitivas, destacam-se além da Inteligência Artificial, o de Memética, que contribuiu, decisivamente, para o significado atual do Darwinismo, conhecido por Darwinismo Neural (também chamado de Reducionismo Voraz). É de Dennett uma bem conhecida argumentação contra os qualia. Segundo ele, o conceito é tão confuso que não pode ser usado ou entendido de forma não contraditória e, por isso, não constitui uma refutação válida para o Fisicalismo.

\subsection{O Eliminativismo}

Por Eliminativismo se entende qualquer ciência que sustente que os entes, a metodologia e os conceitos de tal ciência devam ser eliminados completamente sobre todos os níveis ontológicos, epistemológicos e conceituais e, de fato, aceitarse e estudar-se só de uma ciência o que há de mais fundamental, eliminando, pois, 
qualquer hipótese prévia. É, em certo sentido, uma forma extrema de reducionismo (TRIPICCHIO; TRIPICCHIO, 2004, p. 127).

Um exemplo de conceito eliminado no curso da história é o de phlogiston, matéria ou elemento a partir do qual se supunha surgir o fogo. Uma vez descoberto o fogo como uma reação química baseada no oxigênio, o phlogiston foi completamente esquecido. Ele não foi reduzido ou identificado com o oxigênio, mas efetivamente abandonado. Na Filosofia da Mente, o Eliminativismo sustenta que:

(a) a mente não existe como entidade separada do corpo;

(b) a mente só pode ser estudada através de fenômenos mais fundamentais, como o comportamento ou a ativdade neuronal;

(c) os conceitos usados na Psicologia tradicional são inadaptáveis, vagos e até mesmo errôneros, e, por isso, devam ser eliminados em favor da linguagem da física e da neurologia.

O Eliminativismo propõe-se a eliminar o conceito tradiconal de mente, considerando-a simplesmente um objeto da Física. Leis que descrevem o funcionamento da mente não têm nenhuma característica particular que as tornaria diferentes das outras leis físicas, pois a mente deve ser estudada como qualquer outro fato físico. Assumindo que a mente manifesta-se, preponderantemente, em dois aspectos, o comportamento e o cérebro, o Elimininativismo identifica a mente com essees aspectos, e nega, completamente, uma eventual realidade ou causalidade atrás desses fenômenos. Com isso, de fato, elimina-se todo aspecto físico da mente (DI FRANCESCO, 2002, p. 137).

O Eliminativismo tenta em todo o caso superar o problema mente-corpo, considerando a mente como um conceito errado, concentrando-se só no estudo do cérebro e negando qualquer forma de dualismo. São adeptos do Eliminativismo, dentre outros, Paul Churchland e Patrícia Smith Churchland.

\subsection{O Reducionismo}

O Reducionismo a respeito de qualquer ciência sustenta que os entes, a metodologia e os conceitos de tais ciências devem ser reduzidos ao mínimo suficiente para explicar os fatos. Nesse sentido, o reducionismo pode ser 
compreendido como uma aplicação do princípio de economia, segundo o qual não é necessário aumentar sem necessidade as entidades envolvidas na explicação de um fenômeno.

Existem três formas de Reducionismo:

(a) ontológico (análogo ao monismo);

(b) epistemológico; e

(c) conceitual.

Em particular, o Reducionismo na Filosofia da Mente, a respeito dessas três categorias, sustenta que.

(a) a mente não existe como entidade separada do corpo;

(b) a mente só pode ser estudada através de fenômenos fundamentais, como o comportamento ou atividade neuronal;

(c) os conceitos usados na psicologia tradicional são inadaptáveis, por demais vagos e errôneos;

O Reducionismo propõe estudar a mente reduzindo-a a um objeto da física. Leis que descrevem o funcionamento da mente seriam associadas a leis físicas, e, desse modo, a mente deve ser estudada como qualquer objeto físico. Assumindo que a mente manifesta-se, sobretudo, em dois aspectos, o comportamento e o cérebro, o Reducionismo limita a quaisquer aspectos e se propõe a estudar só estes, sem fazer digressões sobre uma eventual realidade outra ou oculta desses fenômenos. Com isso, de fato, elimina-se possiveis aspectos metafisico da mente (FISETTE; POIRIER, 2003, p. 197).

O Reducionismo tenta, desse modo, superar o problema mente-corpo, reduzindo a mente à propriedade ou aspecto do corpo e negando qualquer forma de dualismo (FISETTE; POIRIER, 2003, p. 323).

As correntes na filosofia da mente e nas Ciências Cognitivas que predicam o Reducionismo são:

(a) o Materialismo;

(b) o Eliminativismo;

(c) o Comportamentismo. 


\subsection{Interacionismo}

O Interacionismo deriva do dualismo e apresenta solução para muitos problemas dessa última posição. O dualismo sustenta que existem duas substâncias fundamentais, que não podem interagir, causalmente, entre si. Na Filosofia da Mente, o dualismo enfrenta da seguinte forma o problema mente-corpo: se mente e corpo são completamente separados e não podem interagir, como podem explicar a grande multitude dos fenômenos dos quais se têm experiência na vida de todo os dias? São exemplos o fato de que se o meu corpo é ferido, é a mente a sentir dor; ou, ainda, é a minha vontade que move o meu corpo. Não obstante, assim também na experiência quotidiana se vê uma grande diferença entre fenômenos físicos e fenômenos psíquicos, como, por exemplo, a intencionalidade ou a diferença entre leis causais e leis associativas (DI FRANCESCO, 2002, p. 147).

O Interacionismo propõe a superação desses problemas explicando como e onde o corpo e a mente interagem. O Interacionismo concorda com o dualismo e assevera que existem em duas substâncias fundamentais, mas admite um certo grau de influência de uma sobre a outra (DI FRANCESCO, 2002).

Essas assertivas dão origem a um segundo problema, aquele da causação mental. Assumindo que no universo reina a causalidade física da matéria em movimento, como se pode admitir uma causalidade imaterial e não submetida às leis da física? Eis porque Descartes e outros filósofos tentaram superar os problemas postos pela adoção do dualismo. Alguns andaram em direção ao Ocasionalismo e outros tentaram várias formas de Interacionismo (DI FRANCESCO, 2002).

\subsection{O Emergentismo}

O Emergentismo em Filosofia da Mente é a corrente que estabelece que a mente seria um fenômeno emergente, ou seja, que os fenômenos mentais seriam propriedades emergentes do cérebro (DI FRANCESCO, 2002, p. 119). Suas principais teses são (DI FRANCESCO, 2002):

(a) a existência de emergência como legítima categoria explicativa do real; 
(b) a aplicabilidade da emergência a fenômenos como a vida, a mente e o fenômenos sociais;

(c) a refutação do Dualismo ontológico, em sua toda sua forma; e

(d) a refutação do Reducionismo, em algumas da suas concepções.

Os emergentistas adotam (DI FRANCESCO, 2002):

(a) a Teoria da evolução natural;

(b) a Teoria da hierarquização do real.

Historicamente, o Emergentismo surgiu da tentativa de achar uma opinião intermediária entre a posição epistemologicamente contraposta: mecanicismo e vitalismo; monismo materialista e cartesiano dualismo; Reducionismo e Holismo; objetivismo cientificista e subjetivismo humanístico. A convicção de que o Emergentismo poderia resolver tais disputas baseia-se no fato de que o conceito de emergência parece em grau de precisar, cientificamente, a antiga ideia de que a totalidade é maior que soma das suas partes de um objeto. Segundo os emergentistas, a totalidade é sempre maior do que a soma das partes. De maneira que as partes ao se somarem tornam-se um quid emergente (DI FRANCESCO, 2002, p. 113).

Os reducionistas de cada lugar ou época, segundo os emergentista, veem só as partes ou, no máximo, a sua soma, e, com isso, negam o que seria o quid emergente. Vitalistas, dualista cartesianos e espiritualistas em geral, de outra parte, confundem o quid emergente com uma substância ontologicamente autônoma e, como tal, supranatural (DI FRANCESCO, 2002).

Segundo o Emergentismo, a controvérsia entre a Epistemologia extremista e falaciosa pode ser resolvida reconhecendo-se a existência e importância do quid emergente, mas, negando-lhe seja a autonomia ontológica, seja a natureza substancial. Todos os fenômenos emergentes compreendidos na mente são fenômenos espontâneos, de natureza, naturalmente gerados no conjunto das interações entre as totalidades das quais emergem (DI FRANCESCO, 2002).

\subsection{O Epifenomenalismo}


Epifenomenalismo é a atitude dualista que afirma ser o físico que produz o mental, mas o mental não tem nenhuma ação sobre o físico. Segundo o Epifenomenalismo, somente há uma única coisa, o corpo, e a mente seria, apenas, resultante do corpo. Dessa maneira, os eventos mentais seriam considerados de causas materiais, não obstante eventos mentais não tenham efeitos materiais. Esses eventos mentais é que seriam os epifenômenos, que não produzem efeitos. Um problema por vezes apontado como epifenomenalista é o de explicar como eventos mentais, que não tem poderes causais e não estão em relações causais, podem ser objetos de memórias (DI FRANCESCO, 2002, p. 154).

Uma pesquisa empírica dá a indicação de que a ocorrência de algum estado cerebral pode, em princípio, ser causalmente explicada pelo recurso unicamente a outros estados físicos. É para justificar esse fenômeno que alguns filósofos aderiram ao Epifenomenalismo, a teoria segundo a qual são estados físicos que causam os estados mentais, mas os estados mentais não causam nada (TRIPICCHIO; TRIPICCHIO, 2004, p. 48).

O Epifenomenalismo sugere que só existe ação psicofísica de mão única a partir do físico para o mental. Como permite esse tipo de ação causal, o Epifenomenalismo pode abranger a teoria causal da percepção. Contudo, quando combinado com o dualismo cartesiano, o Epifenomenalismo, assim como o Interacionismo cartesiano, implica na tese problemática de que os estados de uma substância extensa podem afetar os estados de uma substância inextensa. Um epifenomenalista pode contornar esse problema, rejeitando a opinião de acordo com a qual a mente é uma substância inextensa, embora sustente que os estados e os eventos mentais são distintos dos estados e eventos físicos (HIERRO-PESCADOR, 2005, p. 175).

\subsection{O Computacionalismo}

Por Computacionalismo se entende a concepção segunda a qual cada capacidade, isolada no seu contexto, representa uma série de imput e output, como expressão de uma função de computação. O cérebro, em outros termos, se comporta como uma calculadora de funções computáveis no qual dados por 
constantes imput e estado da máquina serão previsíveis output constantes. J. Fodor escreveu um livro, em 1975, no qual trata das características dessas ideias para um modelo de mente (FODOR, 2002, p. 136). Suas características são (DI FRANCESCO, 2002, p. 153):

(a) todas as funções psicológicas são tratadas como atos de computação, de modo que a mente, como um sistema dinâmico, é descrita por meio de funções de um computador;

(b) as capacidades psicológicas podem ser especificadas independentemente da sua análise, em outros termos que podem ser tomados em consideração isoladamente pelo sistema que a analisa;

(c) a teoria da mente seria capaz de reconhecer e caracterizar os imputs e os outputs relevantes, antes de explicar como os segundos seriam computados pelos primeiros, o que torna, naturalmente, uma direta consequência dos assunto precedente.

Exige-se no Computacionalismo que a capacidade individual seja analisável e devemos assim saber como devem ser computadas as capacidade das quais queremos descrever input e output (HIERRO-PESCADOR, 2005, p. 178).

\subsection{Conexionismo}

Os modelos de explicação dos fatos psicológicos, assim como o Computacionismo, são definidos como modelos top-down: de um estudo das capacidades e dos efeitos observados em psicologia buscamos a derivação do modelo que possa adequar-se, em linha de princípio, às estruturas naturais que constituem o sistema. As neurociências são, por outro lado, como já visto, um sistema de explicação bottom-up. Segundo elas, só do estudo das estruturas biológicas que tornam anatomicamente possível a mente, seria possível buscar a explicação causal dos fenômenos observados pela Psicologia (DI FRANCESCO, 2002, p. 154).

O Conexionismo é também um modelo bottom-up. A partir de modelos elementares de conexões neurais, ele tenta caracterizar modelos sempre mais complexos, destinados a explicar o comportamento; em outros termos, as conexões 
neurais devem ser consideradas o centro das atenções. $E$ a arquitetura das conexões neurais reproduz forma idealizada de fornecer um modelo de satisfação, que na mente é a explicação dos fenômenos psicológicos observados (DI FRANCESCO, 2002).

É evidente que o Conexionismo e o Computacionismo, opostos no procedimento de análise da mente, têm, todavia, alguns pressupostos em comuns: a idéia de uma mente entendida na sua atividade mais propriamente teorética ou de cálculo, e não transposta a um ambiente, influenciada por emoções, sensações e necessidade de adaptação instantânea. É própria essa objeção que, a partir dos anos 80, foi conduzida aos modelos conexionistas e computacionais (FODOR, 2002, p. 334).

\subsection{A Teoria do Naturalismo Biológico de John Searle}

A teoria de Searle contra o paradigma que ele define de Inteligência Artificial faz parte de uma concepção mais ampla da relação mente-corpo. Searle refuta o dualismo e o reducionismo em favor de uma concepção que ele chama de Naturalismo Biologico. Segundo essa forma de pensar, a consciência é um epifenômeno (fenômeno emergente) do organismo e tem propriedades exclusivamente físicas. Como a pressão de um gás dentro de um recipiente fechado é uma propriedade emergente das colisões de muitas moléculas de gás (FISETTE; POIRIER, 2003, p. 219).

Na opinião de Searle, pode-se resumir os conceitos do seguinte modo: dado que a mente possui intencionalidade e o computador não, o computador não pode ter uma mente. O experimento mental do quarto chinês poderia ser interpretado de modo que a sintaxe (a capacidade do computador de seguir um procedimento) não implica na semântica (o fato de o computador saber o que está fazendo) (FISETTE; POIRIER, 2003).

A intencionalidade é um dos argumentos principais usados por Searle na sua contraposição ao conceito de Inteligência Artificial, na sua versão forte, ou seja, aquela que não se limita a considerar o computador como um instumento de indagação da mente humana, mas que se limita a afirmar que, com programas 
próprios, ele se transforma em algo análogo à mente humana e é, então, capaz de compreender e de ter outros estados cognitivos (FISETTE; POIRIER, 2003).

Searle escreve as suas primeiras obras com base nos textos de John Langshaw Austin e Peter Strawson, seus professores, particulamente na obra Atos Linguísticos, de Austin. Searle desenvolveu a análise da intenção comunicativa de Austin, segundo, a qual os objetos de estudos são atos ilocutivos, isto é, que consistem em dizer qualquer coisa (FISETTE; POIRIER, 2003, p. 220).

\subsection{A Teoria da Consciência e da Intencionalidade em Searle}

A força ilocutiva é um conceito baseado em quatro regras. Pode-se generalizar e considerar como caso específico de intencionalidade. Searle identifica uma propriedade dos fenômenos intencionais, que define a direção de adaptação (direction of fit). Por exemplo, quando uma pessoa vê uma flor, o seu estado mental adaptar-se ao estado do mundo. A direção de adaptação é mente-mundo. Mas se uma pessoa estende a mão e colhe a flor, a sua intenção é aquela de adaptar o mundo ao seu próprio estado mental. Assim, a direção torna-se mundo-mente (DI FRANCESCO, 2002, p. 115).

Searle desenvolve também o conceito de background, que ele usa em uma acepção muito técnica, fonte de algumas discussões filosóficas. Segundo Searle, o background é o contexto interno no qual ocorrem os atos intencionais. Isso inclui a compreensão do mundo próprio do indivíduo e compreende também o fato de que outras pessoas possam participar ou participem das suas atividades intencionais (FISETTE; POIRIER, 2003, p. 220).

Searle fornece uma sólida base teórica para o uso do conceito de intencionalidade no interior de um contexto social. Lato sensu, a intencionalidade quer dizer que qualquer um vincula um significado a um objeto, ou mesmo uma própria convicção, a posse, ou o seu contrário, o desapossamento etc. O conceito inclui em si aquilo que é do "intento". No livro Intenções e ações coletivas, Searle propõe-se a definir as intenções coletivas como uma forma específica de intencionalidade. Na sua obra precedente havia fornecido as regras da linguagem e da intencionalidade (FISETTE; POIRIER, 2003). 
Searle apresenta cinco teses que sustentam sua análise (FISETTE; POIRIER, 2003):

1. O comportamento intencional coletivo existe, e não corresponde à soma dos comportamentos intencionais individuais.

2. As intencões coletivas não podem ser reduzidas às intenções individuais.

3. As duas teses precedentes estão compreendidas em dois vínculos.

a. a sociedade é constituída de indivíduos; não existe mente de grupo ou uma "consciência de grupo".

b. a intencionalidade, seja individual ou de um grupo, é independe de ser verdadeira ou falsa.

Com o objetivo de corroborar essa tese, Searle desenvolve uma anotação simbólica da intencionalidade coletiva, que permite vincular uma intenção individual a uma coletiva. Por serem dois tipos de intenção distintos, de fato, uma intenção individual pode ter como resultado uma intenção coletiva. A fim de que se creia em uma intenção coletiva, faz-se necessário que se compreenda que os outros possam participar da mesma intenção. Por isso (DI FRANCESCO, 2002, p. 227):

4. A intencionalidade coletiva pressupõe uma compreensão de fundo (Backgraund sense) de outro ator social, como indivíduo capaz de participar das atividades coletivas.

5. A teoria da intencionalidade, juntamente com o conceito de background, permitem explicar a intencionalidade coletiva.

\section{CONSIDERAÇÕES FINAIS}

Foi discutido no decorrer dessa reflexão o tratamento dessas complexas questões. Este trabalho, além de demarcar os problemas, tentou demonstrar a necessidade de sua superação, para que haja a apropriação e uso das técnicas de Inteligência Artificial na atividade de julgar. Serão apresentados caminhos que conduzem a efetiva possibilidade de utilização das ferramentas da Inteligência Artificial na execução de atividades privativas do Poder Judiciário.

Buscou-se demonstrar que há a existência de apenas dois obstáculos conceituas na formação da vontade do Estado-Juiz para a utilização da Inteligência 
Artificial na elaboração de decisões judiciais. De forma inequívoca, ficou claro que qualquer tentativa no sentido de utilização da Inteligência Artificial na atividade judicial deverá, necessariamente, superar as dificuldades que este trabalho demarca com precisão. A delimitação desses obstáculos, assim como a identificação de suas origens e bases.

\section{REFERÊNCIAS}

DI FRANCESCO, Michele. Introduzione alla filosofia della mente. 9. ed. Roma: Carocci, 2002.

FISETTE, Denis; POIRIER, Pierre. Philosophie de l'esprit. Paris: J. Vrin, 2003.

FODOR, Jerry A. in Philosophie de l'esprit. Paris: J. Vrin, 2002.

HIERRO-PESCADOR, José. Filosofia de la mente y de la ciencia cognitiva. Barcelona: Akal, 2005.

TEIXEIRA, João de Fernandes. Filosofia da mente: neurociênca, cognição e comportamento. São Carlos: Claraluz, 2005.

TRIPICCHIO, Adalberto; TRIPICCHIO, Ana Cecília. Teorias da mente. São Carlos: Tecmedd, 2004. 